\title{
O presente é um passado em potência? Considerações acerca da atitude estética do ser humano em relação aos acontecimentos históricos a partir de Simone de Beauvoir
}

\begin{abstract}
Josiana Barbosa Andrade ${ }^{1}$
Resumo: No terceiro capítulo de Por uma moral da ambiguidade (1947), Simone de Beauvoir desenvolve diferentes temas, entre eles o da "atitude de estética" do ser humano para com os acontecimentos históricos. Essa atitude é definida por um olhar puro e contemplativo do ser humano em relação às diferentes situações humanas no mundo, que resultaria em uma tentativa de fuga da verdade do presente e em uma negação da condição humana. Então, considerando o contexto da crise atual sustida pelo COVID-19, pretendemos mostrar, ao longo deste trabalho, não somente a relação entre essa noção de atitude estética e a teoria da temporalidade da filósofa, mas também suas implicações morais e políticas.

Palavras-chave: Atitude estética - Acontecimento histórico - Contemplação - Presente - Passado

\section{Is the present a potential past? Considerations about the human being's aesthetic attitude towards historical events from Simone de Beauvoir}

Abstract: In the third chapter of The Ethics of Ambiguity (1947), Simone de Beauvoir develops different themes, including the "aesthetic attitude" of the human being towards historical events. This attitude is defined by a pure and contemplative view of the human being in relation to the different human situations in the world, which would result in an attempt to escape the truth of the present and a denial of the human condition. Therefore, considering the current crisis sparked by COVID-19, we intend to show throughout this paper not only the relationship between this aesthetic attitude notion and the philosopher's theory of temporality, but also its moral and political implications.
\end{abstract}

Keywords: Aesthetic attitude - Historical event - Contemplation - Present - Past

\section{Considerações iniciais}

${ }^{1}$ Mestranda em Filosofia pela Universidade Federal de Pelotas. 
Ainda que, ao longo dos anos, o tema da temporalidade, no pensamento de Simone de Beauvoir, tenha sido reduzido, via ad feminam, à dimensão pessoal de sua vida, ele foi também abordado por ela nas dimensões literária e filosófica de sua obra, como pontuou Ursula Tidd ${ }^{2}$ É a partir desta última que conduziremos a nossa problemática no percurso deste artigo: a relação do ser humano para com o presente; a sua atitude estética em relação aos acontecimentos históricos. O problema da temporalidade atravessou toda a obra da filósofa, já sendo retratado tanto em seu primeiro romance publicado, A convidada (19430, quanto em seu inaugural ensaio filosófico, Pirro e Cineias (1944). Contudo, para desenvolvermos o nosso tema proposto, utilizaremos, principalmente, o seu ensaio Por uma moral da ambiguidade $(1947)^{3}$, pela razão de que nele se encontra presente a sua crítica à atitude estética do ser humano no mundo, que seria uma atitude tentadora, principalmente, aos intelectuais e aos artistas, em um período de crise.

No decorrer da atual crise suscitada pelo COVID-19, foram elaborados diferentes trabalhos cujo tema foi o "futuro pós-pandemia", havendo, pois, mais interesse pelo futuro do que pelo presente ${ }^{4}$. Essa é uma das características do que Simone de Beauvoir definiu como atitude estética. A ou o intelectual, ao tentar-se colocar somente como observadora ou observador imparcial do mundo, acaba por esquecer-se de que se encontra nele também como um ser situado. Há, nessa tentativa, uma busca por uma objetividade que beira, em certo sentido, o objetivismo, não somente uma valorização, quase reducionista, da condição de exterioridade do ser humano. O que torna possível, aqui, ainda que esse não seja o nosso objetivo, realizar uma interlocução entre Simone de Beauvoir e Edmund Husserl, uma vez que ele, em sua conferência “A crise da humanidade europeia e a filosofia" (1935), pretendeu mostrar que a crise europeia teria advindo do esquecimento do sentido original da atitude filosófica, enquanto tarefa infinita, em detrimento da atitude científica, em que o cientista esquece-se de que a própria ciência "é produto do espírito que investiga" . A ou o intelectual ou a ou o cientista, nessa perspectiva, não teria claro para si o fundamento próprio de seu trabalho, que teria sua origem em sua própria subjetividade.

Essa tentativa de tornar-se uma observadora ou um observador imparcial do mundo pressupõe uma concepção de ser humano que postula uma separação entre o sujeito e o mundo, tornando impossível a ele possuir a si mesmo e ao mundo, ao mesmo tempo: ao lançarse no mundo, ele esqueceria de si mesmo; ao voltar-se para si, esqueceria do mundo. Essa relação entre o sujeito e o mundo seria, daí, de oposição e contradição, como enfatizou Simone de Beauvoir, em sua resenha "Fenomenologia da percepção de Merleau-Ponty" (1945. Nesse mesmo texto, ela afirma que "um dos grandes méritos da fenomenologia ao ser humano foi o de reestabelecer o direito a uma existência autêntica, eliminando a oposição do

\footnotetext{
2 TIDD, "For the time being: Simone de Beauvoir's representation of temporality", p. 108.

${ }^{3}$ Serão utilizadas as seguintes abreviaturas para citar as obras de Simone de Beauvoir: PC, (Pirro e Cineias), PMA (Por uma moral da ambiguidade), RFP (Resenha da "Fenomenologia da percepção de Merleau-Ponty”), QPL ("Que Peut la Littérature?”), com a seguinte estrutura: obra em francês / tradução, quando houver.

${ }^{4}$ Dentre esses trabalhos, encontram-se artigos jornalísticos tais como "Como o coronavírus vai mudar nossas vidas: dez tendências para o mundo pós-pandemia" (abril, 2020) de Clayton Melo; "E o pós-Brasil" [abril, 2020], de Rafael R. Ioris e Antonio A. R. Ioris; a série textos "O mundo Pós-Covid-19", da Ecoa, organizada por Mariana Castro; a coletânea de artigos Brasil pós-pandemia (2020), organizada por Ronaldo Pereira Santos e Marcio Pochmann.

${ }^{5}$ HUSSERL, Europa: crise e renovação, p. 151.
} 
sujeito e do objeto", em que o movimento da posse de si e do mundo ocorreria, simultaneamente. E ainda, em sua análise, ela pontua que em tal livro de Merleau-Ponty "a condição humana estaria em jogo"7, pois o filósofo havia mostrado que a atitude fenomenológica permitiria ao ser humano a realização de si e o desvelamento do mundo, mediante um movimento contínuo de presentificação de si. Com essa possibilidade da realização de uma existência autêntica, a atitude estética, enquanto olhar puro e imparcial, revelar-se-á inautêntica, como veremos, ao longo deste estudo, na medida em que ela se revelará não apenas como uma fuga da verdade do presente, mas também como uma tentativa de negação da condição humana.

\section{O ser humano como ser situado}

Para evidenciarmos as implicações morais e políticas da atitude estética do ser humano em relação aos acontecimentos históricos, devemos, antes de tudo, compreender a perspectiva beauvoiriana acerca da condição humana. Segundo ela, o ser humano, originalmente, surge no mundo como uma falta de ser, mas a ele é permitido realizar-se como uma existência. Aqui, dois pontos fazem-se importantes enunciar: primeiro, que essa falta de ser do ser humano não conduz, automaticamente, a um desejo de ser'; e segundo, que é possível identificar uma diferença entre vida e existência na filosofia de Simone de Beauvoir, como pontuou Andrea Veltman', em que a vida seria definida como um fato que não possui em si uma justificativa, e a existência, como uma busca para a justificação da vida, originalmente, injustificada. A existência, à vista disso, aparece nos textos beauvoirianos tanto como o fato da vida humana que foi lançada no mundo quanto como uma maneira de assumir a condição humana de ser falta de ser. Por isso, ainda que o ser humano, inicialmente, surja no mundo como uma falta de ser, ela precisa tornar-se, fazer-se, uma existência. Esse "tornar-se" e "fazerse" uma existência não questiona, todavia, o axioma existencialista de que a existência (enquanto vida humana) é um fato, mas problematiza as maneiras de viver a condição humana de ser uma negatividade, já que, para Simone de Beauvoir, o ser do ser humano "é

\footnotetext{
${ }^{6}$ RFP, p. 07 / p. 160.

${ }^{7}$ RFP, p. 07 / p. 160.

${ }^{8}$ Frequentemente, foi-se defendido, nos estudos do pensamento de Simone de Beauvoir, que a sua moral de Por uma moral da ambiguidade pressupõe e defende a ontologia sartreana. Recentemente, por exemplo, Beatrís da Silva Seus retomou e levou a suas últimas consequências, em Simone de Beauvoir e a libertação da mulher: do existencialismo sartriano à moral da ambiguidade (2019), o argumento ad feminam de que a obra de Simone de Beauvoir seria, filosoficamente, dependente da de Sartre; segunda ela, Simone de Beauvoir "buscou dar continuidade ao tratado moral incompleto de Sartre (O ser e o nada), trazendo em seu conteúdo o mesmo tipo de fundamentação analítica de homem, mas focando no âmbito moral" (SEUS, Simone de Beauvoir e a libertação da mulher: do existencialismo sartriano à moral da ambiguidade, p. 113). Ocorre, no entanto, que em seu ensaio supracitado, a filósofa não concorda com a condição humana apresentada por Sartre, escrevendo que, em O ser e o nada, "há "uma descrição do homem (sic! ser humano) sério e de seu universo" (PMA, p. 67 / p. 43), ao invés de uma apresentação da verdadeira condição humana. À diferença de Sartre, ela não realiza uma associação necessária entre a falta de ser e o desejo de ser; para ela, o ser humano não é, ontologicamente, desejo de ser. Esse desejo, como bem pontuou Debra Bergoffen, na filosofia beauvoiriana, é histórico; ele está vinculado com a nostalgia da infância - momento no qual o existente se relaciona com o mundo de maneira séria, sem ser um sério, entendendo seriedade, aqui, como uma maneira de ser que busca justificar a si mesmo e os dados do mundo de forma necessária e incondicional (cf. BERGOFFEN, "Introduction". In: SIMONS, LE BON DE BEAUVOIR, Philosophical Writings: The Beanvoir Series, p. 84).

9 VELTMAN, "Transcendence and imanence in Beauvoir's Ethics", p. 121.
} 
ser falta de ser, mas há uma maneira de ser dessa falta que é precisamente a existência" ${ }^{\prime 10}$. E essa maneira, conforme ela, é a que escolhe querer desvelar o ser, ao invés de querer ser o $\operatorname{ser}^{11}$.

Nesse contexto, a existência - qua maneira de assumir a falta de ser - aparecerá como um contraditório em relação às outras maneiras de assunção dessa falta de ser, as quais visam não um tornar-se existência, mas um tornar-se ser, uma pura positividade, um ser acabado, cheio de si. Ora, enquanto a busca de fazer-se uma existência implica uma contínua justificação de si que parte da aceitação de ser uma falta de ser, a busca de fazer-se um ser resulta numa contínua "justificação" de si que parte da negação de ser uma falta de ser. Na primeira, Simone de Beauvoir identificará a postura autêntica da assunção da condição humana, e na segunda, consequentemente, a postura inautêntica. Essa assunção autêntica - de aceitar-se como falta de ser e buscar tornar-se uma existência - ocorre, segundo a filósofa, mediante ao que ela nomeou de conversão existencialista; por meio desta, o ser humano aceita-se como falta de ser, nega essa falta como falta e afirmar-se como existência positiva ${ }^{12}$. Nessa conversão, dois movimentos estão presentes: o da suspensão fenomenológica e o da dialética ${ }^{13}$. No primeiro, o existente realiza uma suspensão de si, por meio da qual the é revelado a sua verdadeira condição humana - a de ser uma falta de ser; e no segundo, a partir dessa revelação do primeiro movimento, o existente elabora um movimento dialético visando converter a sua falta de ser em existência, isto é, ele busca criar uma justificação e significado para si no mundo sem querer negar a sua condição de ser uma negatividade, mas continuamente afirmála e convertê-la. A condição para a autenticidade, como podemos perceber, está vinculada com a realização da conversão existencialista, em que o existente almeja não querer ser o ser, e sim desvelá-lo. E isso vai ao encontro do que Simone de Beauvoir indicou em sua resenha supracitada, ao associar a autenticidade ao movimento de desvelamento, em que o existente tomaria posse de si e do mundo, simultaneamente.

É-nos possível dizer, diante disso, que a falta de ser e a existência, na filosofia beauvoiriana, não são sinônimos, ainda que sejam indissociáveis, uma vez que o movimento de fazer-se existência depende da condição humana de ser falta de ser, que não pode, aliás, ser superada, mas tão-somente convertida ${ }^{14}$. O ser humano situado no mundo e, por sua vez, no espaço, no tempo e na história, que busca realizar a conversão de si, é, a um só tempo, falta de ser e existência; ao mesmo tempo, as suas obras elaboradas no mundo - que refletem a sua busca por justificação de si - tendem a serem transcendidas, haja vista a condição da temporalidade e, por essa razão, a conversão de si contínua revela-se necessária, já que uma justificação acabada de si não seria possível. Essa condição humana de ser negatividade e positividade traz à tona ainda a concepção de ser humano, na perspectiva de Simone de Beauvoir: a de que ele é, estruturalmente, uma ambiguidade. Essa ambiguidade, contudo, não está vinculada à ideia de imprecisão, mas à de paradoxo ${ }^{15}$. Dizer que o ser humano é uma ambiguidade, em sentido beauvoiriano, significa dizer que ele é, simultaneamente, facticidade e liberdade, objeto e sujeito, corpo e espírito. O existente, então, não deve buscar superar a sua ambiguidade a fim de se afirmar somente como liberdade, sujeito ou espírito; ao

\footnotetext{
${ }^{10}$ PMA, p. 17 / pp. 17-18.

11 PMA, p. 42 / p. 30.

12 PMA, p. 18 / p. 18.

13 PMA, pp. $18-19$ / p. 18.

${ }^{14}$ ANDRADE, Simone de Beauvoir e Carolina de Jesus, p. 28.

15 PMA, p. 13 / p. 15.
} 
contrário, precisa assumi-la. Essa assunção ocorre mediante a conversão. Simone de Beauvoir não propõe à maneira de Sartre uma busca do ser, mas uma busca da existência ${ }^{16}$. E a existência reflete, aqui, a assunção da ambiguidade de ser facticidade e liberdade, objeto e sujeito, corpo e espírito. Dessa ambiguidade original, outras surgem, dentre as quais se encontra a de que o ser humano existe no mundo como um indivíduo singular e como uma coletividade. E, novamente, não se deve tentar eliminá-la, mas assumi-la, ainda que, normalmente, a tendência seja a lógica excludente: ou tenta-se reduzir o ser humano à sua individualidade, ou tenta-se englobá-lo dentro de uma coletividade. Contra essa postura reducionista, Simone de Beauvoir, em concordância com Sartre, trouxe à baila a noção de que o ser humano seria uma "totalidade-destotalizada" ", a qual está vinculada a condição de ser ambiguidade. Para ela, afirmar que o ser humano é uma totalidade-destotalizada significa dizer que ele é um ser que só faz desfazendo-se, que é uma realidade cujo desígnio original é manter-se uma abertura ao mundo e aos outros. Cada indivíduo singular dentro de uma coletividade relaciona-se com os outros de forma singular, sempre em situação; e cada um, a partir de sua situação singular, relaciona-se com essa coletividade inteligível.

O ser humano, dessa maneira, sempre existe em situação no mundo. Tal situação é definida não somente como um lugar concreto na terra, mas também pela forma que o existente se relaciona com esse lugar ${ }^{18}$. Essa noção foi retratada, em um primeiro momento, por Simone de Beauvoir, através de sua metáfora do jardim de Cândido, na primeira parte de Pirro e Cineias $^{19}$; por isso, Debra Bergoffen argumentou que, por meio dessa metáfora, a filósofa revela a estrutura da liberdade humana como liberdade situada, a qual só se realiza por meio da ação ${ }^{20}$. Nela, dois elementos relevantes para a jovem Simone de Beauvoir se evidenciam: a relação do ser humano para com o mundo precisa ser fundada por ele próprio, em situação; a realidade de um ser humano é sempre delimitada a partir de seus atos. O existente é definido por aquilo que ele far. Ele precisa enraizar-se no mundo, ainda que "jamais lhe seja permitido realizar-se" ${ }^{21}$ em sua totalidade, considerando a sua condição de ser falta de ser. Mais tarde, em seu escrito "Que peut la littérature?” (1960), Simone de Beauvoir apresenta uma concepção de situação mais refinada, que não contradiz a de seu primeiro ensaio filosófico, em que considera com maior precisão a condição humana de ser facticidade e liberdade, ao trazer à baila a noção conceitual. A situação é também constituída por tudo aquilo que forma a individualidade do indivíduo situado - o seu passado, a sua classe, a sua condição, os seus projetos ${ }^{22}$. A situação, assim, pode ser compreendida como um entrelaçamento de todas as ambiguidades e experiências vividas de um ser humano em relação situada com o mundo.

\footnotetext{
16 Sobre esse tema, ver Simone de Beauvoir e Carolina de Jesus: um ensaio sobre a busca da existência, 2020, de Josiana Andrade.

17 PMA, p. 176 / 2005, p. 100.

18 ANDRADE, Simone de Beawvoir e Carolina de Jesus: um ensaio sobre a busca da existência, p. 30.

${ }^{19}$ PC, p. 13 / p. 137.

${ }^{20}$ BERGOFFEN, "Introduction (Pyrrhus and Cineas)", p. 82.

${ }^{21}$ PMA, p. 188 / p. 106.

22 QPL, p. 335.
} 


\section{A atitude estética como fuga da verdade presente}

Vimos que o ser humano, conforme a perspectiva beauvoiriana, é um existente situado cuja condição de existir, autenticamente, encontra-se na ação de desvelar o mundo, visando converter, ao invés de negar, a sua negatividade. Nesse desvelamento, por conseguinte, ele engendra novos significados em mundo com significados e sentidos já constituídos, como apontou Thana de Souza ${ }^{23}$. Por esse motivo, o mundo, segundo Simone de Beauvoir, "é um mundo humano em que cada objeto é penetrado por significação; é um mundo falante, de onde se elevam solicitações, apelos; compreende-se assim que através desse mundo cada indivíduo possa dar conteúdo concreto à sua liberdade" 24 . O mundo envolve o existente, que envolve e é envolvido; tal como o ser humano, é uma totalidade-destotalizada. O que significa dizer que, embora ele seja o mesmo para todos, a forma como cada uma e cada um se relaciona com ele é singular ${ }^{25}$, sendo definido, assim, como um "entrelaçamento de experiências singulares que se envolvem enquanto permanecem separadas" 26 , pela filósofa. Esse "envolver" o mundo pressupõe que o ser humano esteja nele, como um sujeito situado no tempo, no espaço e na história, impossibilitando-o de se lançar como uma consciência atemporal e impessoal, na medida em que é lançado no mundo em situação e o experiencia mediante o espaço ${ }^{27}$. Contudo, nem todo ser humano busca reconhecer a sua própria condição de existir no mundo, há aquele que com ele pretende se relacionar somente pela via contemplativa, esquecendo-se de que é também corpo; essa atitude, Simone de Beauvoir definiu como atitude estética.

A pessoa que adota a atitude estética "pretende não ter com o mundo nenhuma outra relação que não a de uma contemplação desinteressada; fora do tempo, longe dos homens [sic! seres humanos], ele se põe diante da história, à qual não acredita pertencer, como um olhar puro" 28 . Nessa passagem, podemos perceber que há nesse sujeito contemplativo uma busca por superar a sua condição de ser ambiguidade, tendo em conta que se colocar "fora do tempo" ou "diante da história" é negar-se enquanto um ser que é tanto facticidade quanto liberdade. Além disso, essa busca possui sua origem, possivelmente, em uma concepção humana que vê o corpo como um limite para a liberdade, que pode ser encontrada, em certa medida, nos estoicos; ou no dualismo cartesiano do corpo e espírito, que postula uma dicotomia e, por conseguinte, uma hierarquia, em que o espírito é colocado como superior ao corpo. Essa postura contemplativa, por dedução, seria considerada superior por quem a escolhe. Ao realizar essa atitude estética, o existente não somente esquece de sua condição de ser ambiguidade, mas também acredita em uma mentira: de que seria possível colocar-se fora do tempo e da história estando dentro da terra.

A pessoa que adere a essa atitude, porém, não é apenas inautêntica e imoral, no sentido de que não busca realizar a assunção e conversão de si no mundo, mas também perigosa: a sua "visão impessoal iguala todas as situações" 29 , apreendendo-as com certa

\footnotetext{
${ }^{23}$ SOUZA, "Beauvoir e a situação das mulheres: entre subjetividade e facticidade", p. 224.

24 PMA, p. 107 / p. 64.

${ }^{25}$ ANDRADE, Simone de Beauvoir e Carolina de Jesus: um ensaio sobre a busca da existência, p. 19.

${ }^{26}$ QPL, p. 337. Tradução nossa.

${ }^{27}$ Simone de Beauvoir enfatiza esse aspecto em sua resenha "Fenomenologia da percepção de Merleau Ponty".

${ }^{28}$ PMA, p. 108 / p. 65.

${ }^{29}$ PMA, p. 108 / p. 65.
}

: : : Cadernos de Ética e Filosofia Política | Número 38 (1) | 1º semestre de 2021 | Página 151 : : : 
indiferença. No decorrer da atual crise decorrente do COVID-19, sobretudo em seus primeiros meses, essa atitude pôde ser percebida na sabedoria popular ${ }^{30}$, em textos jornalísticos ${ }^{31}$ e nas discussões teóricas sobre a crise. Um dos seus primeiros reflexos, no contexto da sociedade em geral, no Brasil, foi a ideia de que o vírus seria "democrático", de que todos os seres humanos estariam "no mesmo barco", já que esse vírus invisível não distinguiria classe, gênero e raça. Uma das primeiras discussões teóricas, dentro do contexto filosófico, foi o tema da pós-pandemia, tratando a realidade presente como um momento transitório da História, privilegiando, em demasia, somente o aspecto da pura exterioridade da condição humana, em que os seres singulares são percebidos somente como unidades contabilizáveis, ou como passividades abstratas que seguem, sem revoltas e perdas definitivas, o rumo da História. Dentre esses teóricos, encontra-se Slavoj Žižek, que mesmo se posicionando como "observador não especialista munido de um acesso muito limitado a dados" 32 , especulou sobre a possibilidade de um novo comunismo, de novos sistemas de solidariedade, de novas formas de viver decorrentes da crise atual. Seu argumento foi o de que "mesmo acontecimentos horríveis podem ter consequências positivas imprevistas" 33 . É uma hipótese. Mas por que ir direto para as consequências possiveis, ao invés de olhar para o presente como um existente situado que está também envolvido por ela? Podemos identificar, ao longo da leitura da coletânea de artigos de Žižek, a atitude estética conforme o sentido beauvoiriano. Neles, o filósofo, mais do que entender o fenômeno atual em sua ineditez, visa possíveis consequências no futuro, com uma tendência universalista. Concordando com o vice-ministro de saúde iraniano, Iraj Harirchi, que afirmou que "esse vírus é democrático e não discerne entre pobres e ricos ou entre políticos e cidadãos comuns" ${ }^{34}$, Žižek escreveu, precipitadamente, que estávamos "no mesmo barco", sendo "difícil não ver a ironia suprema no fato de que o que nos uniu e o nos levou à solidariedade global se expressa no nível da vida cotidiana em orientações rigorosas para evitar contatos próximos com os outros e inclusive se autoisolar" ${ }^{35}$. Não por acaso, ele teve que reconsiderar, por muitas razões, algumas de suas posições, como observou Boaventura de Sousa Santos, que nos mostrou que as e os intelectuais não devem partir de suas próprias teorias elaboradas em "tempos normais" para compreender a realidade em "excessão excepcional”, e sim "estar atentos às necessidades e às aspirações dos cidadãos comuns e saber partir delas para teorizar" $" 36$.

Ainda que o vírus seja invisível e possível a todos os seres humanos, as situações humanas são diferentes e singulares e, portanto, as formas de relacionar com ele também. Os indivíduos, como vimos, vivem sempre em situação, que reflete todos os elementos que

\footnotetext{
${ }^{30}$ Em "O existencialismo e sabedoria das nações", Simone de Beauvoir apresenta um método que nos permite compreender algumas contradições entre o espírito ideal e a realidade brutal presente na sabedoria popular, as quais estão vinculadas com a não aceitação do caráter finito da existência humana, como mostrou Eleanore Holveck na introdução da obra Philosophical Writings: The Beauvoir Series. O que permitiria ao ser humano, na cotidianidade, pular de um plano da verdade para o outro. Por exemplo, em um momento como o atual, existe, ao mesmo tempo, uma ênfase tanto no escândalo das milhares de mortes quanto na concepção de presente como transitório que será justificado com o surgimento de melhores formas de viver, nessa sabedoria.

31 Ver nota 4.

32 ŽIŽEK, 2020a, [n.p.].

33 ŽIŽEK, 2020a, [n.p.].

34 ŽIŽEK, 2020a, [n.p.].

35 ŽIŽZEK, 2020a, [n.p.].

36 SANTOS, A cruel pedagogia do vírus, [n.p.].
} 
constituem a sua individualidade. Em um período próximo ao que Žižek escreveu que estávamos no mesmo barco, uma das primeiras mortes no Brasil acontecera: uma mulher negra de 63 anos, trabalhadora doméstica, cuja contaminação deu-se por meio do convívio com sua patroa, que acabava de retornar de Itália e trouxera consigo o vírus; ambas foram infectadas, mas somente a primeiro veio a óbito ${ }^{37}$. A situação das duas não era a mesma, ainda que o vírus o fosse. As verdades da pandemia do COVID-19 não são reveladas, primeiramente, na teoria, mas na realidade vivida pelos seres humanos; uma dessas verdades foi a de que patroas e empregadas não estão no mesmo barco; a pandemia pode significar para uns, por exemplo, o tédio, e para outros, a fome. Por isso, um acontecimento histórico, segundo Simone de Beauvoir, "não é uma passagem, mas uma realidade singular" 38 e precisa ser vivida como tal.

Quando uma pessoa que adere à atitude estética olha para o acontecimento histórico presente, ela tende a negar realidade concreta do agora em proveito do espaço-temporal universal, não apreendendo a verdade do presente, mas, ao contrário, dela fugindo. A esse ponto de vista da História, Simone de Beauvoir estabeleceu uma crítica, ao realizar uma análise do sistema hegeliano, uma vez que a história humana se revelaria, no final das contas, como uma "interminável sequência de negações que jamais retornam ao positivo; toda ação seria destruição, e a vida, uma fuga vã" ${ }^{39}$. O indivíduo, em Hegel, sendo somente substância do real, na medida em que o Sujeito é o Espírito, sacrifica-se com a promessa de que a recuperação do real encontraria sua forma positiva no seio do Espírito Absoluto. Mas, como pontuou a filósofa, algumas dificuldades surgiriam, pelo fato de que o próprio Hegel havia reconhecido a impossibilidade da ideia de um futuro imóvel, "uma vez que o Espírito é inquietude, a dialética da luta e da reconciliação jamais poderia ser interrompida: o futuro que ele considera não é paz perpétua de Kant, mas um estado de guerra indefinido" ${ }^{40}$. Disso, nasce um problema: se Espírito jamais realiza a reconciliação do real, por que os indivíduos deveriam se sacrificar? Então, "a plenitude hegeliana logo passa do nada à ausência. E a própria grandeza desse fracasso faz brilhar a verdade: somente o sujeito pode justificar sua própria existência" 41 .

Se não existe um futuro fixo a nossa espera, a angústia de viver e sentir o presente como uma realidade singular vem à tona. É disso que a pessoa que adere à atitude estética pretende escapar, ao se colocar como observadora do mundo, considerando "com imparcialidade os fatos contingentes" ${ }^{\prime 2}$. Uma filosofia da necessidade, que engendra um fim incondicional futuro com objetivo de justificar, sem angústia, as ações no presente, torna-se consoladora. O presente, então, é concebido "somente como um negativo que deve ser suprimido enquanto tal"43; "uma existência transitória que é feita para ser abolida"44. Por outro lado, uma concepção fatalista da história, como observou Simone de Beauvoir, torna arbitrárias e absurdas as escolhas humanas realizadas no plano da contingência; o sofrimento

\footnotetext{
37 Sobre esse noticiário, ver "Patroas, empregadas e coronavírus", de Débora de Diniz e Giselle Carino, publicado no Elpaís, em 21 de março de 2020.

38 PMA, p. 175 / p. 100.

39 PMA, p. 151 / p. 87.

40 PMA, p. 152 / p. 87.

${ }^{41}$ PMA, p. $152-153$ / p. 88.

42 PMA, p. 110 / p. 66.

43 PMA, p. 168 / p. 96.

44 PMA, p. 168 / p. 96.
} 
humano de uma existência singular torna-se injustificado e as vítimas, anônimas. "Se o desenrolar da história é fatal, não há mais lugar para a angústia da escolha, nem para o arrependimento, nem para o escândalo; nenhuma revolta pode mais brotar em nenhum coração" ${ }^{45}$. Nessa concepção, as ações no presente não seriam tratadas como fins, e sim como meios, que estariam justificados, tendo em vista a fatalidade pressuposta. Poder-se-ia, então, justificar milhares de mortes sem a angústia da decisão.

O presente não é tratado como "provisório" em detrimento de um futuro qualquer, mas de um "futuro-mito", no qual algumas antinomias das ações humanas seriam superadas. Por esse motivo, não foi por acaso que Slavoj Žižek especulou sobre a possibilidade de novas formas de viver decorrentes da crise atual ${ }^{46}$, antes de querer compreender a própria crise conforme ela está a se apresentar. É verdade que a situação suscitada pelo COVID-19 mostrou que os seres humanos são capazes de criar valores novos, o que evidencia a verdade da condição humana defendida por Simone de Beauvoir, mas disso não se segue que tais valores serão baseados na solidariedade, necessariamente. Essa certeza não é possível ao ser humano. Nessa busca por um futuro ideal há, na verdade, uma tentativa de superar o fracasso que é próprio da condição humana, uma vez que ele nunca pode se realizar completamente. O surgimento de uma nova sociedade mais humanizada daria um sentido positivo aos acontecimentos devastadores do presente, ao passo que a possibilidade do fracasso humano evidenciaria a arbitrariedade das mortes, do sofrimento humano. É disso que a pessoa que assume a atitude estética em relação ao acontecimento histórico escandaloso tenta fugir. $\mathrm{O}$ acontecimento do COVID-19 converte-se em positividade, ao pensar-se no futuro com melhorias a partir dele. Ora, não foi por acaso, ou por puro otimismo, que Žižek argumentou no início da pandemia que "mesmo acontecimentos horríveis podem ter consequências positivas imprevistas" ${ }^{47}$. Mas essa atitude, ainda que abstrata e completiva, ocorre dentro do mundo; o próprio ato de contemplar é um fazer e, ao realizá-lo, cria-se significado no mundo, mas com uma diferença em relação à atitude autêntica: há nessa atitude somente criação de significado no mundo, mas não de sentido para a própria vida.

\section{O significado do presente}

A pessoa que adota a atitude estética, no sentido do olhar puro e imparcial, assume em certo sentido a falta de ser, mas não para tornar-se existência, e sim para escapar do mundo concreto, sendo a sua vida diluída no universal. Ao fazer isso, ela fracassa, pois ao ser humano não é permitido sair do mundo: "pôr-se 'fora' é ainda uma maneira de viver o fato inelutável de que se está dentro" 48 . Aqueles que pretendem, "em nome da história, da arte, da poesia dominar o drama da época, querendo ou não, [são] os seus atores" ${ }^{49}$. Assim, conforme Simone de Beauvoir, "é para o artista, para o escritor, que o problema se põe de maneira mais aguda ao mesmo tempo equívoca; pois não é em nome da pura contemplação,

\footnotetext{
45 PMA, p. 157 / p. 90.

46 Pode-se consultar sua obra Pandemia: Covid-19 e a reinvenção do comunismo; ou sua entrevista, publicada dia 08 de abril de 2020, pelo Instituto Humanitas Unisinos: "Vejo um novo comunismo, distante do comunismo histórico, brotar do vírus".

47 ŽIŽEK, Pandemia: Covid-19 e a reinvenção do comunismo, [n.p.]

48 PMA, p. 110 / p. 66.

49 PMA, p. 110 / p. 66.
}

: : : Cadernos de Ética e Filosofia Política | Número 38 (1) | 1º semestre de 2021 | Página 154 : : 
mas de um projeto definido, que se pretende afirmar então a indiferença das situações humanas" ${ }^{50}$. Nas mãos de uma escritora ou de um escritor, de uma ou um artista ou de uma ou um cientista essa relação de "contemplação" para com o mundo pode transformar-se em uma obra. Dependendo do caso, ela revela-se perigosa, na medida em que a escritora ou o escritor, com o seu olhar imparcial, pode transfigurar, por meio de uma encantadora narrativa, um horror em uma admiração, tornando a miséria e a injustiça, por exemplo, um deleite para a leitora ou o leitor.

O presente, por conseguinte, "não é um passado em potência; ele é o momento da escolha e da ação, não podemos evitar vivê-lo através de um projeto" ${ }^{1}$. É no presente que o ser humano se enraíza no mundo, ao negá-lo, ele busca negar a sua própria presença nele. Ao elaborar um texto sobre a pandemia, uma ou um intelectual está escolhendo e agindo no mundo, ainda que pretenda se colocar numa posição de observadora ou observador; nessa ação, há o engendramento de novos significados e sentidos acerca da crise que podem resultar em outros, pois todos os movimentos humanos realizados no mundo, segundo a filósofa, podem servir de pontos de partidas para os outros. Uma palavra escrita no presente sobre a crise não é somente uma palavra, é uma realidade concreta. E o presente, em Simone de Beauvoir, não pode ser pensado sem o passado e sem o futuro, uma vez que, no presente, há uma relação tanto com o passado quanto com o futuro. Por isso, o tornar-se existência significará também, conforme ela, ser "capaz de amarrar o passado, o presente e o futuro" 52 , de "construir" um tempo através da consciência interna do tempo. A conversão de si, da falta de ser em existência, é também uma constante síntese temporal de si. E se o existente faz do presente um passado em potência rumo ao futuro, os seus projetos presentes tendem a estabelecer uma dissociação entre o passado e o futuro, pois o que os entrelaça é o presente; pensar em futuro-mito, em um momento de crise como a do COVID-19, é uma tentativa de dissociar o presente do futuro e, por sua vez, do passado, na medida em que os valores da sociedade atual refletem os do passado, ainda que ela esteja sendo atravessada por um fenômeno com aspectos inéditos. E, exatamente, por ter uma dimensão inédita é que esse fenômeno precisa ser olhado na medida em que aparece.

O existente, porém, ao realizar uma escolha, não o faz arbitrariamente; ele leva em consideração não somente os seus momentos no passado, mas também as possibilidades abertas do futuro. A questão que é o cerne do problema é o que se pensa quando se fala em futuro. Este, para Simone de Beauvoir, "está tão estreitamente ligado ao presente que compõe com ele uma única forma temporal; é esse futuro que Heidegger considera como uma realidade dada a cada instante" ${ }^{25}$. E, por essa razão, a ideia de futuro-mito reflete uma espécie de ruptura com o passado, de modo que não seria um prolongamento do presente. "A palavra futuro", segundo a filósofa, "tem dois sentidos, correspondentes aos dois aspectos da condição ambígua, que é falta de ser e é existência, é ao mesmo tempo como ser e como existência que ele é visado" ${ }^{54}$. A ambiguidade do ser humano, daí, está diretamente vinculada com a temporalidade. Ele precisa se realizar, a um só tempo, como ser e devir, como falta de ser e existência, como presente rumo ao futuro, sem negar o presente como

\footnotetext{
${ }^{50}$ PMA, p. $111 /$ p. 66.

51 PMA, p. 110 / p. 66.

52 RFP, p. 10 / p. 163.

53 PMA, p. 167 / p. 95.

54 PMA, pp. 166-167 / p. 95.
} 
presente. Por ser a sua condição sempre superar a si mesmo, faz-se necessário a ele realizar uma contínua síntese temporal de si, em que resgata o passado no presente visando um futuro. Por isso, a ambiguidade, como já afirmamos, está associada ao paradoxo, ao invés da imprecisão. O ser humano é e não é, simultaneamente; sua existência "só é fazendo-se ser; de tal maneira que, precisamente, é apenas na medida em que deve ser conquistada que ela se dá" 55 . O seu futuro, enquanto humano, é sempre um futuro finito; o futuro-mito, por transcender a própria realidade humana, tende a tornar-se inumano.

É-nos possível dizer, assim, que o ser humano só existe, em situação no mundo, de forma concreta, singular e finita. Ele, desse modo, não deveria olhar a História como uma "totalidade racional", mas como uma "totalidade-destotalizada". O acontecimento histórico do COVID-19, que estamos a sentir, tentando compreendê-lo, não se apresenta como uma totalidade-totalizada, não só por causa do tempo, mas também porque é sempre de maneira destotalizada que o apreendemos, ainda que ele seja uma totalidade enquanto um fundo histórico comum de diferentes sociedades. Essa concepção da História como totalidadedestotalizada, indica Simone de Beauvoir, "não contradiz a de uma inteligibilidade histórica; pois não é verdade que o espírito deve optar entre o absurdo contingente do descontínuo e a necessidade racionalista do contínuo: cabe-lhe, ao contrário, destacar sobre o fundo único do mundo uma pluralidade de conjuntos coerentes" ${ }^{56}$. O acontecimento do COVID-19, à luz disso, não é nem puramente contingente nem puramente necessário; é a maneira como o ser humano se relaciona com ele que lhe gera sentido e significado. À pessoa observadora imparcial que adota a atitude estética diante do acontecimento, ele tende a se apresentar como uma facticidade dada, seja ela de um ponto de vista contingente ou necessário. Mas acontece que enquanto "totalidade-destotalizada", o acontecimento é vivenciado no mundo por diferentes coletividades e indivíduos singulares, que não se excluem, necessariamente, entre si, mas que podem engajar-se em vista de uma meta comum, sobre um fundo do tempo. $\mathrm{O}$ existente, consequentemente, não precisa conhecer todas as variedades de um fenômeno para pode agir; ele deve agir na incerteza e no risco que toda decisão implica. Seu ponto de vista é sempre destotalizado.

A ideia de que é preciso ter conhecimento e certeza acerca de um fenômeno para agir pode gerar no existente a inércia ou a crença em um futuro-mito, em que todas as ações no presente já seriam vistas como justificadas, como indicamos acima. Correlata à ideia do futuro-mito, a ideia do presente como "provisório", permite gerar a possibilidade de uma amoralidade na política, uma vez que se poderia argumentar, como já foi registrado ao longo da história, que o ser humano só reencontraria a possibilidade real de uma ação moral, em uma situação de estabilidade. E se for o caso de ter que esperar por essa situação, a ação moral será vista apenas como uma promessa. A ação moral, daí, sempre está por vir, nunca é. Essas ideias, aliás, estão no cerne das discussões do pós-pandemia, que ultrapassam o presente somente como condição para o futuro. Ocorre que o presente é, como indicamos, a um só tempo, um meio e um fim, e se o tratarmos somente como um meio, ele sempre será provisório; e se o presente sempre for provisório, a realidade humana também o será, haja vista que esta ${ }^{57}$ só existe, de maneira concreta, no presente. Então, ao realizar a sua crítica à dialética pura e necessária, a filósofa não a nega, mas a desmitifica, tendo em conta que pode

55 PMA, p. 35 / p. 26.

${ }^{56}$ PMA, p. 176 / p. 100.

${ }^{57}$ PMA, p. 178 / p. 101.

: : : Cadernos de Ética e Filosofia Política | Número 38 (1) | 1º semestre de 2021 | Página 156 : : : 
haver um movimento dialético histórico, sem a ideia de um futuro-mito ou de um fim incondicional, que tornaria o presente justificado a priori.

\section{Considerações finais}

Diante disso, podemos afirmar que para que o ser humano "tenha um mundo a expressar, é preciso primeiro que ele esteja situado nesse mundo, oprimido ou opressor, resignado ou revoltado"58; é preciso que ele seja humano entre os outros seres humanos, situado no espaço, no tempo e na história. É somente quando se assume como uma existência situada que as situações humanas não lhe aparecem equivalentes, mas diferentes e singulares. E, a partir daí, ele poderá encontrar razões para desvelar o mundo no presente, com o objetivo de justificar a si mesmo nele; a sua criação de significado no mundo não será separada de sua criação de sentido para si: elas se realizarão em um único movimento. Acontece, no entanto, que nem todas as pessoas querem-se situadas. Essa característica, como vimos, encontra-se no que Simone de Beauvoir nomeou de atitude estética, que pode ser identificada, sobretudo, em intelectuais. À vista disso, buscamos mostrar, ao longo deste estudo, uma relação entre a atitude estética do ser humano em relação a um acontecimento histórico e a teoria da temporalidade beauvoiriana, considerando o contexto da crise atual suscitada pelo COVID-19. Para isso, dividimo-lo em três momentos. No primeiro, apresentamos a perspectiva beauvoiriana acerca da condição humana, a fim de evidenciar não somente a diferença entre a assunção autêntica e inautêntica dessa condição humana que consiste em ser falta de ser, mas também as noções de ambiguidade e situação da filósofa. No segundo, à luz que foi exposto no primeiro momento, mostramos o que define a atitude estética diante de um acontecimento histórico e algumas de suas implicações, entre as quais estaria tanto a negação contínua do presente em detrimento do futuro, na medida em que para a pessoa que adota tal atitude, o presente é concebido como um passado em potência, quanto a negação da condição humana de ser ambíguo e situado, o que nos conduziu a dizer que a atitude estética é também uma forma inautêntica de viver a condição humana; além

disso, realizamos ainda uma interlocução com Žižek, que se encontra entre os filósofos a escrever sobre a crise, em uma perspectiva do pós-pandemia. No terceiro, considerando os momentos precedentes, buscamos definir o significado do presente conforme a filosofia beauvoiriana, explicitando a sua crítica à atitude estética do ser humano, que se posiciona como um observador do mundo, como se não tivesse situado no espaço, no tempo e na história, o que o direciona a aderir a um ponto de vista universal da História. E, com o seu olhar puro e imparcial, ele tende a transformar os acontecimentos históricos singulares em particulares cuja essência não se encontra nelas mesmas, mas em uma totalidade racional e universal; a justificar o presente a partir de um futuro-mito.

Por fim, é-nos possível dizer que o presente não é, para Simone de Beauvoir, um passado em potência. A sua crítica à atitude estética do ser humano em relação aos acontecimentos históricos, vinculada com a sua teoria da temporalidade, permitiu-nos compreender que o presente é, ao mesmo tempo, fim e meio, não somente uma passagem, uma transição rumo ao futuro. Se ignorarmos a existência do presente como um fim, não nos será possível sentir o fim como um fim, porque a própria ideia de fim perde todo o seu

58 PMA, p. 113 / p. 67.

: : : Cadernos de Ética e Filosofia Política | Número 38 (1) | 1º semestre de 2021 | Página 157 : : : 
sentido. Se olharmos para a crise atual do COVID-19 somente como um momento a ser transcendido ao longo da História, não sentiremos quando ela terminar, já que sua existência era ser apenas um momento da História, um passado em potência. Ela precisa, pois, ser vivenciada tal como ela aparece. Certamente, ela se constituirá como parte da história da humanidade, mas isso não implica dizer que ela não possuirá uma história singular conforme cada contex to em que ela surgiu. À diferença das pessoas que aderem à atitude estética, aquelas que, parafraseando Simone de Beauvoir, fazem dessa crise a sua crise, sentirão quando ela chegar ao seu fim, encontrando motivo para celebrar ${ }^{59}$.

\section{Referências bibliográficas}

ANDRADE, Josiana. Simone de Beawvoir e Carolina de Jesus: ensaio sobre a busca da existência. São Leopoldo: Karywa, 2020. [e-book]

BERGOFFEN, Debra. The philosophy of Simone de Beauvoir: Gendered Phenomenologies, Erotic Generosities. Albany: State University of New York Press, 1997.

"Introduction". In: SIMONS, Margaret; LE BON DE BEAUVOIR, Sylvie. Philosophical Writings: The Beauvoir Series. Chicago: University of Illinois Press, 2004.

DE BEAUVOIR, Simone. Pyrrbus et Cinéas. Paris: Gallimard, 1944.

2005.

Pirro e Cinéias. Trad. de Marcelo Jacques de Moraes. Rio de Janeiro: Nova Fronteira,

O existencialismo e a sabedoria das nações. Trad. de Manuel de Lima e Bruno da Ponte.

Lisboa: Minotauro, 1965.

Por uma Moral da Ambiguidade. Trad. de Marcelo Jacques de Moraes. Rio de Janeiro: Nova Fronteira, 2005.

Pour une morale de l'ambiguïté. Paris: Gallimard, 1947.

"A Review of The Phenomenology of Perception by Maurice Merleau-Ponty". In: SIMONS, Margaret; LE BON DE BEAUVOIR, Sylvie. Philosophical Writings: The Beauvoir Series. Chicago: University of Illinois Press, 2004.

"La Phénoménologie de la perception de Maurice Merleau-ponty". In: Éditions de Minuit, n. 144, 2020.

\footnotetext{
59 Simone de Beauvoir mostra, a partir do acontecimento do fim da ocupação nazista em França, o sentido da festa cujo "papel é interromper o movimento da transcendência, pôr o fim como fim". "Todos", escreveu ela, "os que haviam feito desse combate o seu combate, nem que fosse apenas pela sinceridade de suas esperanças, também olhavam a vitória como uma vitória absoluta, qualquer que tivesse que ser o futuro. Ninguém era ingênuo o bastante para ignorar que logo a infelicidade encontraria outras faces; mas aquela estava banida da terra, absolutamente" (PMA, p. 181 / p. 103).
} 
. “Que Peut la Littérature?” In: LECARME-TABONE, Éliane; JEANNELLE, JeanLouis. L’Herne. Beauvoir. Paris: Éditions de L’Herne, 2012.

HOLVECK, Eleanore. “Introduction”. In: SIMONS, Margaret; LE BON DE BEAUVOIR, Sylvie. Philosophical Writings: The Beauvoir Series. Chicago: University of Illinois Press, 2004.

HUSSERL, Edmund. Europa: crise e renovação. Trad. de Pedro M. S. Alves e Carlos Aurélio Morujão. Rio de Janeiro: Forense Universitária, 2014.

SANTOS, Boaventura de Sousa. A cruel pedagogia do vírus. São Paulo: Boitempo, 2020. [ebook]

SEUS, Beatrís da Silva. Simone de Beauvoir e a liberação da mulher: do existencialismo sartriano à moral da ambiguidade. Porto Alegre: Fi, 2019.

SOUZA, Thana. "Beauvoir e a situação das mulheres: entre subjetividade e facticidade". In: Ethi@@, Florianópolis, v. 17, n. 2, pp. 217-237, 2018.

TIDD, Ursula. "For the time being: Simone de Beauvoir's representation of temporality". In: O'BRIEN, Wendy (Ed.). The Existential Phenomenology of Simone de Beawvoir. Nova York: Springer Verlag Press, 2001.

VELTMAN, Andrea. "Transcendence and Immanence in Beauvoir's Ethics”. In: SIMONS, Margaret. The Philosophy of Simone de Beauvoir. Bloomington: Indiana University Press, 2006.

ŽIŽEK, Slavoj. Pandemia Covid-19 e a reinvenção do comunismo. Trad. de Arthur Renzo. São Paulo: Boitempo, 2020a. [e-book]

"Vejo um novo comunismo, distante do comunismo histórico, brotar do vírus". Entrevista com Slavoj Žižek. In: Revista IHU-Online, São Leopoldo, 08 abr. 2020b. Disponível em: http://www.ihu.unisinos.br/78-noticias/597903-vejo-um-novo-comunismo-distantedo-comunismo-historico-brotar-do-virus-entrevista-com-slavoj-zizek. 